Medknow

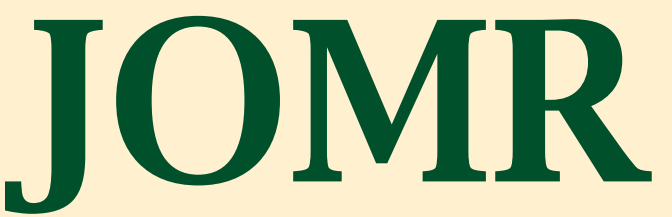

Q. Wolters Kluwer

ISSN 2347-9906 Journal of Obesity and Metabolic Research http://www.jomrjournal.org January $2016 \cdot$ Volume $3 \cdot$ Issue 1
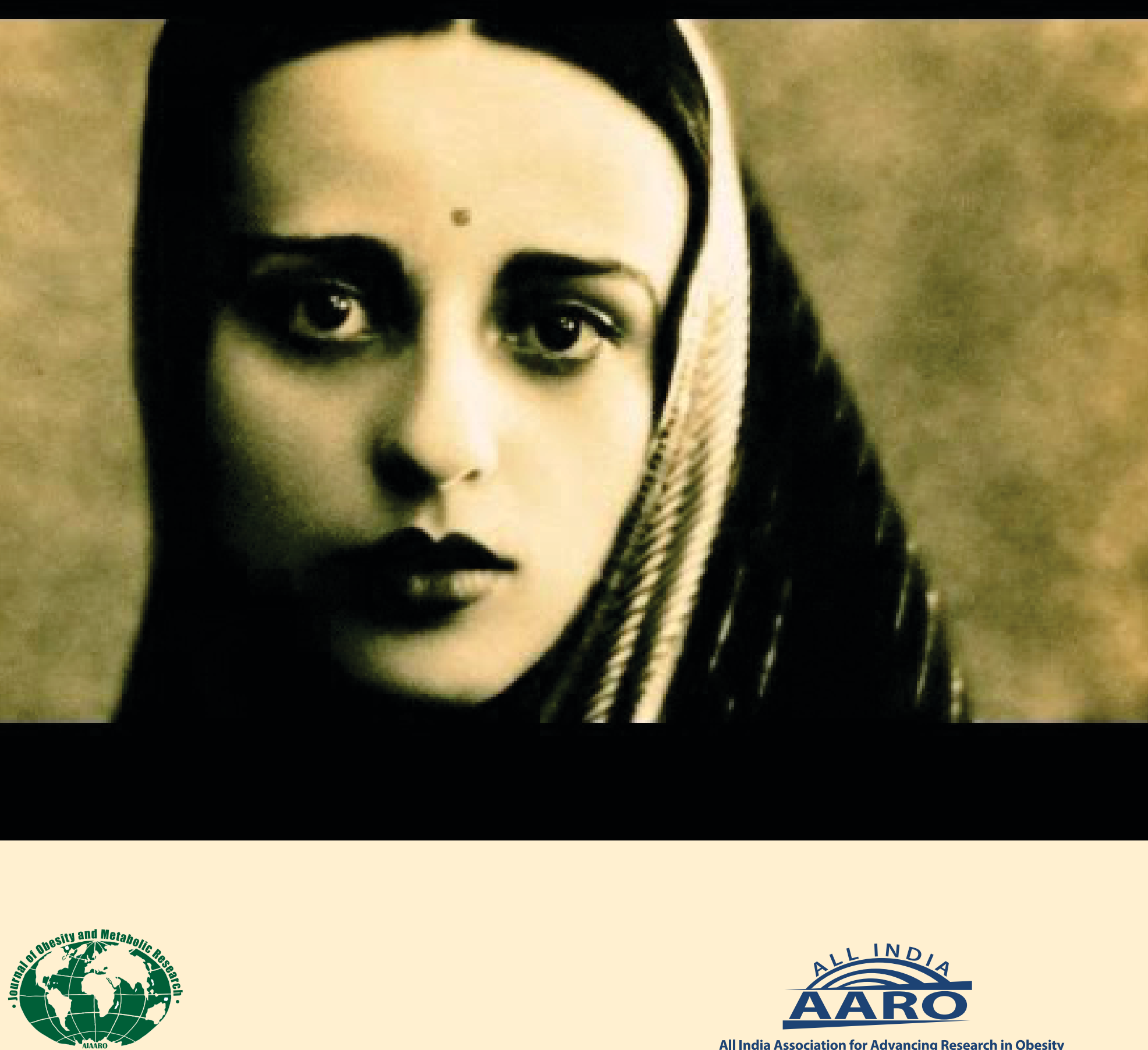


\title{
Relationship Between Body Adiposity and Arterial Stiffness in Young Indian Adults
}

\author{
Jeyasundar Radhakrishnan, Narasimman Swaminathan', Natasha Pereira D'Souza', \\ Samantha Carneiro ${ }^{1}$, Gretel Goveas ${ }^{1}$, Dionne Matthew, Keiran Henderson, David A. Brodie
}

\begin{abstract}
Background: Obesity is one of the major cardiovascular risk factors and is linked with arterial stiffness. This study was undertaken to establish the relationship between regional adiposity and arterial stiffness using simple noninvasive techniques. Methods: In total, 181 young Asian Indian adults aged 18-28 years (mean age $21.9 \pm 2.2$ ) were measured for adiposity and arterial stiffness. Total body fat percentage was derived from skinfold thickness of various body sites. Body mass index and waist-hip-ratio were also measured. Arterial stiffness was measured using a SphygmoCor with a carotid-radial pulse wave analysis technique. Results: Significant gender differences were observed on anthropometric variables including skinfold thickness $(P<0.05)$ and all the arterial stiffness variables $(P<0.05)$ except pulse wave velocity. Systolic pressure, augmentation pressure, augmentation index (AIx), AIx at 75\% heart rate, and aortic systolic pressure had statistically significant correlations with all three adiposity variables $(P<0.05)$. Significant correlations were found in a higher number of variables in the females. Physical activity had negative correlations with arterial stiffness and adiposity variables $(P<0.05)$. Conclusion: Arterial stiffness measured by carotid-radial pulse wave analysis is strongly related to adiposity measured from skinfold thickness in females. Females had higher arterial stiffness and adiposity compared with men. These findings could be helpful in future research using noninvasive arterial stiffness measurements.
\end{abstract}

Key words: Adiposity, arterial stiffness, obesity, pulse wave analysis, skinfold thickness

\section{INTRODUCTION}

$\mathbf{O}$ besity is one of the important risk factors for diabetes and other cardiovascular disease. The World Health Organization has declared that ischemic heart disease will be ranked first, and diabetes will move from $11^{\text {th }}$ place to $6^{\text {th }}$ place for the global burden of diseases and mortality by $2030 .^{[1]}$ In 2005, it was estimated that $33 \%$ of the world's adult population were overweight or obese. Further, it is projected that there will be up to $57 \%$ overweight or

Cardiovascular Health Research Group, Faculty of Society and Health, Buckinghamshire New University, Uxbridge UB8 1NA, UK, 'Department of Physiotherapy, Father Muller Medical College and Hospital, Mangalore, Karnataka, India

Received May 27, 2015 and in revised form Feb 19, 2016. Accepted for publication Feb 24, 2016

\begin{tabular}{|l|l|}
\hline \multicolumn{2}{|c|}{ Access this article online } \\
\hline Quick Response Code: & Website: \\
\hline & www.jomrjournal.org \\
\hline & \\
\hline
\end{tabular}

obesity levels by $2030 .{ }^{[2]}$ Obesity prevalence is observed in developed as well as developing counties such as India. In India, it is projected that there will be an increase of the prevalence of overweight or obesity from $16.9 \%$ (as in 2005 ) to $32.8 \%$ by $2030 .{ }^{[2]}$ In India, obesity was observed even in school aged preadolescents and adolescents in both males and females. There was higher prevalence in high socioeconomic children and females. ${ }^{[3]}$

\section{Arterial stiffness and obesity}

Arterial stiffness is one of the key tools in the measurement of cardiovascular risk. Many studies have confirmed the relationship between arterial stiffness and adiposity in different age groups. ${ }^{[4-7]}$ A strong relationship between adiposity and arterial distensibility using ultrasound

This is an open access article distributed under the terms of the Creative Commons Attribution-NonCommercial-ShareAlike 3.0 License, which allows others to remix, tweak, and build upon the work non-commercially, as long as the author is credited and the new creations are licensed under the identical terms.

For reprints contact: reprints@ medknow.com

How to cite this article: Radhakrishnan J, Swaminathan N, D'Souza NP, Carneiro S, Goveas G, Matthew D, et al. Relationship between body adiposity and arterial stiffness in young Indian adults. J Obes Metab Res 2016;3:3-10. 
imaging was found in British adolescents. ${ }^{[4]}$ In addition to adiposity, physical fitness and lifestyle also influence arterial stiffness. ${ }^{[5]}$ Physical activities have a strong correlation with the incidence of obesity in adolescents and young adults. ${ }^{[8]}$ Body mass index (BMI) is a standard method of assessing overall obesity. Skinfold thickness and waist-hip circumferences are used to measure adiposity in specific parts of the human body. Acree et $a l^{\left[{ }^{[6]}\right.}$ found that obesity was associated with decrease in large and small artery compliance. In their study, large arterial compliance had significant correlations with the skinfold thickness and small arterial compliance with the waist-hip circumferences and their ratios. Total adiposity and truncal subcutaneous fat accumulation at the age of adolescence had positive correlations with the carotid intima-media thickness at the age of 36 in a longitudinal study. ${ }^{[7]}$ Juonala et al..$^{[9]}$ also found that childhood obesity was related to the development of carotid stiffness in adulthood. Interestingly, Zebekakis et $a l^{[10]}$ found that carotid distensibility decreased with higher BMI. They state that the arterial stiffness was modulated with age, i.e., the negative effects of obesity on arterial stiffness were higher in younger age groups. They also suggest studying whether obesity in young adults is related to a higher risk of arterial stiffness and cardiovascular disease. It could help find the potential of preventing obesity at younger age.$^{[10]}$ Most of the studies using noninvasive pulse wave analysis have measured carotid-femoral pulse wave velocity (PWV). The current study aims to use and establish the importance of carotid-radial PWV, which is less intrusive.

To the investigators' knowledge, no study has been carried out to find the relationship between adiposity and arterial stiffness in young and healthy Indian adults. The current study aims to study the relationship between adiposity using skinfold thickness and arterial stiffness using pulse wave analysis in young Indian adults. It was hypothesized that in young healthy Indian adults, there would be a significant positive relationship between body fat percentage measured by skinfold thickness and arterial stiffness measured by a noninvasive pulse wave analysis. There would be significant differences between males and females in the above said relationship. Also, there would be a significant relationship between abdominal obesity and arterial stiffness.

\section{METHODS}

The participants aged 18-28 years (mean age $21.9 \pm 2.2$ ) were recruited from a student population in Mangalore, India, and 181 volunteered to participate.

\section{Skinfold thickness}

The skinfold thickness was measured using a Harpenden Skinfold Caliper (Quality Measurement Limited, Victoria Road Burgess Hill, RH15 9LB United Kingdom).
Measurements were taken according to the manufacturer's guidelines.

Measurement was taken on healthy, undamaged, and uninfected dry skin. The participants were instructed to keep the muscles relaxed during the test. All the measurements were taken on the right side of the body. An exception was made in case of a deformity in the right limb. The skinfold site was marked using a water-soluble ink marker. A tape measure was used to find the accurate mid-points. Each skinfold was firmly grasped by the thumb and index finger, using the pads at the tip of the thumb and finger. Then, the assessor gently pulled the skinfold away from the body, placed the caliper with its dial facing up, perpendicular to the true double fold of skin thickness, and on the site marked, the caliper was applied at approximately $1 \mathrm{~cm}$ below the assessor's finger and thumb. While maintaining the grasp of the skinfold, the caliper was allowed to release so that full tension was placed on the skinfold. After the grip was fully released for $1-2 \mathrm{~s}$, the dial was read to the nearest $0.50 \mathrm{~mm}$. Two measurements were taken at each site and averaged. The measurements were repeated if the two measurements varied by more than $1 \mathrm{~mm}$. The skinfold measurement was taken from seven sites as follows. Chest measurements were taken only on male participants.

- Site 1: Biceps - the anterior surface of the biceps midway between the anterior fold and the antecubital fossa

- Site 2: Triceps - a vertical fold on the posterior midline of the upper arm, over the triceps muscle, halfway between the acromion process (bony process on top of the shoulder) and olecranon process (bony process on elbow). The elbow should be extended and the arm relaxed

- Site 3: Subscapular - the fold is taken on the diagonal line coming from the vertebral border to between 1 and $2 \mathrm{~cm}$ from the inferior angle of the scapula (a diagonal fold about $1-2 \mathrm{~cm}$ below the point of the shoulder blade and $1-2 \mathrm{~cm}$ toward the arm)

- Site 4: Suprailiac - a diagonal fold above the crest of the ilium at the spot where an imaginary line would come down from the anterior auxiliary line, just above the hipbone and $2-3 \mathrm{~cm}$ forward

- Site 5: Chest (juxta-nipples) - a diagonal fold taken one-half of the distance between the anterior auxiliary line and the nipple (the anterior auxiliary line is the crease where the top of the arm when hanging down, meets the chest)

- Site 6: Abdominal - the vertical fold taken at the lateral distance of approximately $2 \mathrm{~cm}$ from the umbilicus ( $2 \mathrm{~cm}$ to the side of the umbilicus)

- Site 7: Thigh - a vertical fold on the anterior aspect of the thigh, midway between the hip and knee joints (on the front of the thigh halfway between the hip joint, where the leg bends when the knee is lifted, and the middle of the knee cap). The leg should be straight and relaxed. 
The body fat percentage was calculated using the linear regression equations of Durnin and Wormersley and Siri's equation [Table 1]. ${ }^{[11]}$ The four skinfold measurements of biceps, triceps, subscapular, and suprailiac were used in this equation.

The Siri's equation fat percentage $=$ ([4.95/body density] -4.5$) \times 100$.

\section{Arterial stiffness measurement}

Participants were asked not to smoke for $3 \mathrm{~h}$ before the study. Measurements were performed while subjects were in a quiet environment after at least $10 \mathrm{~min}$ of supine rest. Local blood pressures were assessed using a conventional measurement of the ipsilateral brachial artery blood pressure using a validated oscillometric device (BP-300 Kernel Int'l Corp. 1F., No. 96, Lane 31, Sec. 1, Sanmin Rd., Banciao Dist., New Taipei City 22070, Taiwan, R.O.C). The mean of three brachial blood pressure values was used for the autocalibration in the measurement of arterial stiffness. Arterial stiffness was assessed with a SphygmoCor system (SCOR-PVx, Version 8.0, AtCor Medical Inc North America, One Pierce Place, Suite 225W, Itasca, IL, 60143, USA). The SphygmoCor is one of the recently developed computerized portable and simple to use devices to assess pulse waveforms and one of the common systems in use for measuring arterial stiffness. It uses an arterial applanation tonometer for recording pressure waveforms that include $\mathrm{PWV}$, pulse pressure (PP), augmentation pressure (Aug. P), augmentation index (AIx), AIx corrected for heart rate at 75 bpm (AIx@HR75), subendocardial viability ratio, and ejection duration. An electrocardiogram recording during measurements is used for synchronization of carotid and radial pulse wave times and heart rate.

The flat tonometer's end was placed on the arterial site with a small amount of pressure, and the waveforms were displayed on the personal computer screen. A $10 \mathrm{~s}$ of stable waveforms with a satisfactory quality were captured and fed into the SphygmoCor system. An averaged pulse waveform was derived from the recording using the integral software. A validated general transfer function was used and aortic pressure waveform was derived. A computer algorithm, comparable to invasive techniques, was used to derive AIx

Table 1: Body density constants

$17-19$ years $20-29$ years $30-39$ years $40-49$ years $50+$ years

\begin{tabular}{cccccc}
\hline Male & & & & & \\
$\mathrm{C}$ & 1.162 & 11631 & 1.1422 & 1.162 & 1.1715 \\
$\mathrm{M}$ & 0.063 & 0.0632 & 0.0544 & 0.07 & 0.0779 \\
Female & & & & & \\
$\mathrm{C}$ & 1.1549 & 1.1599 & 1.1423 & 1.1333 & 1.1339 \\
$\mathrm{M}$ & 0.0678 & 0.0717 & 0.0632 & 0.0612 & 0.0645 \\
\hline
\end{tabular}

Body density $=\mathrm{C}\left(\mathrm{M}\left[\log _{10}\right.\right.$ sum of all four skinfolds $\left.]\right) . \mathrm{C}, \mathrm{M}=$ Predicted constant values of various age groups for body density from the ascending aortic waveform. Brachial artery PP was derived from the difference between systolic and diastolic blood pressures. Aortic PP was assessed from radial artery waveforms applying a radial-to-aorta transfer function.

PWV was measured from sequential recording of ipsilateral carotid and radial waveforms. A foot to foot comparison of these two waveforms was used. PWV was calculated as the "distance:transit time ratio" and is expressed as meter per second. All reported data are mean values of three consecutive high-quality recordings. Care was taken to place the transducers over the same point of the arteries and the same distance was used.

\section{Calculations and statistical analysis}

Abdominal obesity was determined using the International Federation of Diabetes's guidelines (waist circumference $\geq 90 \mathrm{~cm}$ in men and $\geq 80 \mathrm{~cm}$ in women).

Data were analyzed using a software package, SPSS 18 (IBM Corporation 1 New Orchard Road, Armonk, New York 10504-1722, USA). A Kolmogorov-Smirnov test was applied to test the normality of the data. A Pearson correlation test was used to analyze the relationship between the adiposity and arterial stiffness variables. The meaningfulness of the correlation coefficient was evaluated by calculating the coefficient of determination $\left(r^{2}\right)$. An independent $t$-test was used to find the difference in the measured values between males and females. Statistical significance was indicated if $P<0.05$.

\section{RESULTS}

\section{Gender differences}

In total, 124 females and 57 males participated. The physical characteristics of the participants were (mean \pm standard deviation) height $(\mathrm{cm})-162.3 \pm 11.0$, weight $(\mathrm{kg})-58.8 \pm 10.9$, and BMI $-22.1 \pm 3.0 \mathrm{~kg} / \mathrm{m}^{2}$. More than half of the participants engaged in no physical activity. The duration of their physical activity per day was categorized as follows: $>60 \mathrm{~min}-15.4 \%$, 30-60 min - 15.4\%, <30 min - 9.4\%, and none $-59.1 \%$.

The differences in the variables between males and females are listed in Table 2. There were significant differences in height and weight between males and females, but there was no difference in their BMI. There were significant differences in the anthropometric variables between males and females except abdomen skinfold thickness. Abdominal obesity was found in $1.9 \%$ males and $15.9 \%$ females. There were significant differences in all the arterial stiffness variables except PWV. This was especially the case for females, who had a two-fold higher AIx than in the males. 
Radhakrishnan J, et al.: Body adiposity and arterial stiffness

\begin{tabular}{|c|c|c|c|c|c|c|c|}
\hline Variables & Sex & Mean \pm SD & Significant & Variables & Sex & Mean \pm SD & Significant \\
\hline \multirow[t]{2}{*}{ Height $(\mathrm{cm})$} & Male & $169.5 \pm 14.9$ & $* *$ & $\begin{array}{l}\text { SEVR } \\
\end{array}$ & Male & $158.26 \pm 26.1$ & $* *$ \\
\hline & Female & $159.0 \pm 6.3$ & & & Female & $126.36 \pm 22.7$ & \\
\hline \multirow[t]{2}{*}{ Weight $(\mathrm{kg})$} & Male & $66.9 \pm 10.4$ & $* *$ & $\mathrm{BP}(\mathrm{mmHg})$ & Male & Systolic: $121.1 \pm 9.9$ Diastolic $80.2 \pm 7.7$ & $* *$ \\
\hline & Female & $55.1 \pm 9.0$ & & & Female & Systolic $110.5 \pm 0.9$ Diastolic $74.9 \pm 9.2$ & \\
\hline \multirow[t]{2}{*}{ BMI $\left(\mathrm{kg} / \mathrm{m}^{2}\right)$} & Male & $22.7 \pm 2.6$ & NS & HR (bpm) & Male & $69.05 \pm 8.9$ & $* *$ \\
\hline & Female & $21.8 \pm 3.1$ & & & Female & $77.85 \pm 9.8$ & \\
\hline \multirow[t]{2}{*}{ Fat $\%$} & Male & $20.89 \pm 4.5$ & $* *$ & Waist (cm) & Male & $80.4 \pm 8.1$ & $* *$ \\
\hline & Female & $31.31 \pm 3.8$ & & & Female & $72.1 \pm 8.2$ & \\
\hline \multirow[t]{2}{*}{$\mathrm{PWV}(\mathrm{m} / \mathrm{s})$} & Male & $8.00 \pm 1.1$ & NS & Hip (cm) & Male & $95.3 \pm 7.4$ & $*$ \\
\hline & Female & $7.96 \pm 1.0$ & & & Female & $92.15 \pm 6.4$ & \\
\hline \multirow[t]{2}{*}{ Aug. P (mmHg) } & Male & $1.23 \pm 2.4$ & $* *$ & Waist-hip & Male & $0.84 \pm 0.1$ & $* *$ \\
\hline & Female & $4.36 \pm 2.8$ & & & Female & $0.77 \pm 0.1$ & \\
\hline \multirow[t]{2}{*}{ AIx } & Male & $7.34 \pm 8.3$ & $* *$ & SFT chest $(\mathrm{mm})$ & Male & $13.99 \pm 6.2$ & \\
\hline & Female & $15.88 \pm 8.7$ & & & Female & Not measured & \\
\hline \multirow[t]{2}{*}{ AIx at 75} & Male & $4.54 \pm 8.5$ & $* *$ & SFT biceps (mm) & Male & $9.77 \pm 10.5$ & $* *$ \\
\hline & Female & $17.23 \pm 8.3$ & & & Female & $16.84 \pm 8.8$ & \\
\hline \multirow[t]{2}{*}{ Aortic PP (mmHg) } & Male & $26.09 \pm 5.3$ & $*$ & SFT triceps (mm) & Male & $14.30 \pm 4.8$ & $* *$ \\
\hline & Female & $23.98 \pm 6.3$ & & & Female & $20.73 \pm 9.4$ & \\
\hline \multirow[t]{2}{*}{ Aortic SP (mmHg) } & Male & $107.20 \pm 8.2$ & $* *$ & SFT thigh $(\mathrm{mm})$ & Male & $22.79 \pm 8.8$ & $* *$ \\
\hline & Female & $100.17 \pm 9.6$ & & & Female & $34.57 \pm 8.0$ & \\
\hline \multirow[t]{2}{*}{ Aortic DP (mmHg) } & Male & $81.13 \pm 7.7$ & $* *$ & SFT sub scapular (mm) & Male & $17.18 \pm 7.2$ & $*$ \\
\hline & Female & $76.23 \pm 8.9$ & & & Female & $14.77 \pm 4.8$ & \\
\hline \multirow[t]{2}{*}{ Mean P (mmHg) } & Male & $93.38 \pm 7.7$ & $* *$ & SFT abdomen (mm) & Male & $26.34 \pm 10.7$ & NS \\
\hline & Female & $87.80 \pm 8.8$ & & & Female & $26.29 \pm 5.9$ & \\
\hline \multirow[t]{2}{*}{ Ejection duration (ms) } & Male & $36.26 \pm 3.7$ & $* *$ & SFT iliac crest (mm) & Male & $21.47 \pm 9.9$ & $*$ \\
\hline & Female & $41.66 \pm 4.2$ & & & Female & $18.70 \pm 5.9$ & \\
\hline
\end{tabular}

**Significant at $P<0.01, *$ Significant at $P<0.05$. NS: Not significant, BMI: Body mass index, PWV: Pulse wave velocity, SP: Systolic pressure, DP: Diastolic pressure, SEVR: Subendocardial viability ratio, HR: Heart rate, Aug. P: Augmentation pressure, AIx: Augmentation index, SFT: Skinfold thickness, PP: Pulse pressure, SD: Standard deviation

\begin{tabular}{|c|c|c|c|}
\hline \multicolumn{4}{|c|}{$\begin{array}{c}\text { Table 3: Relationship between arterial stiffness measures and } \\
\text { body fat percentage (correlations coefficients) }\end{array}$} \\
\hline Variables & Fat percentage & BMI & Waist-hip-ratio \\
\hline Pulse wave velocity & 0.042 & 0.025 & 0.021 \\
\hline Aug. P & $0.306^{* *}$ & $0.224 * *$ & $0.325^{* *}$ \\
\hline AIx & $0.210^{*}$ & $0.264 * *$ & $0.274 * *$ \\
\hline AIx at 75 & $0.413 * *$ & $0.217 * *$ & $0.340 * *$ \\
\hline Aortic PP & $0.274 * *$ & 0.046 & 0.055 \\
\hline Aortic SP & $0.256 * *$ & $0.294 * *$ & $0.269 * *$ \\
\hline Aortic DP & 0.095 & $0.349 * *$ & $0.270 * *$ \\
\hline Mean pressure & 0.167 & $0.333^{* *}$ & $0.271 * *$ \\
\hline Ejection duration & $0.540 * *$ & 0.058 & $0.203^{*}$ \\
\hline SEVR & $-0.514 * *$ & -0.031 & 0.173 \\
\hline SP & $0.330^{* *}$ & $0.309 * *$ & $0.309 * *$ \\
\hline DP & 0.104 & $0.345^{* *}$ & $0.276^{* *}$ \\
\hline HR & $0.461 * *$ & 0.048 & 0.152 \\
\hline
\end{tabular}

**Significant at $P<0.01, *$ Significant at $P<0.05$. SP: Systolic pressure, DP: Diastolic pressure, SEVR: Subendocardial viability ratio, Aug. P: Augmentation pressure, AIx: Augmentation index, BMI: Body mass index, PP: Pulse pressure, HR: Heart rate

\section{Relationships}

The relationships between the adiposity and arterial stiffness variables are listed in Table 3. Systolic pressure, Aug. P, AIx, AIx@HR75, and aortic systolic pressure had statistically significant correlations with all three adiposity variables. There was no significant relationship

6 Vol. 3, Issue 1, Jan-Mar 2016 found between fat percentage and BMI with gender combined [Table 3], but a significant relationship was established when the data were analyzed separately [Table 4]. AIx had a significant negative correlation with height $(r=-0.329, P=0.0001)$.

There were no significant correlations between fat percentage derived from skinfold thickness and any of the arterial stiffness variables in males. Mean pressure and aortic systolic pressure had a significant correlation with waist-hip-ratio (WHR). The females' adiposity variables had significant correlations with a greater number of arterial stiffness variables, including Aug. P, AIx, and mean pressure.

The participants who had higher physical activity scores had significantly less fat percentage. However, BMI had nonsignificant correlations and WHR had a positive correlation with physical activity [Table 5]. Most of the arterial stiffness variables had negative correlations with physical activity [Table 5].

\section{DISCUSSION}

\section{Influence of gender and physical characteristics}

Any discussion of correlation must take into account the contribution to the total variance. This study showed a 
Radhakrishnan J, et al.: Body adiposity and arterial stiffness

\begin{tabular}{|c|c|c|c|c|c|c|}
\hline \multirow[t]{2}{*}{ Variables } & \multicolumn{3}{|c|}{ Male } & \multicolumn{3}{|c|}{ Female } \\
\hline & Fat percentage & BMI & WHR & Fat percentage & BMI & WHR \\
\hline Fat percentage & & $0.607 * *$ & $0.327 *$ & & $0.556^{* *}$ & $0.250 *$ \\
\hline BMI & & & 0.183 & & & $0.382 * *$ \\
\hline Pulse wave velocity & 0.160 & 0.154 & 0.054 & 0.106 & 0.100 & 0.036 \\
\hline Aug. P & 0.001 & 0.083 & 0.241 & $0.279 * *$ & $0.214 *$ & $0.284 * *$ \\
\hline AIx & 0.159 & 0.222 & 0.001 & $0.320 * *$ & $0.231 *$ & 0.165 \\
\hline AIx at 75 & 0.011 & 0.092 & 0.239 & 0.264 & 0.202 & $0.254 *$ \\
\hline Aortic PP & 0.088 & 0.001 & 0.182 & 0.183 & 0.094 & $0.227 *$ \\
\hline Aortic SP & 0.019 & 0.153 & $0.349 *$ & 0.168 & $0.302 * *$ & 0.014 \\
\hline Aortic DP & 0.025 & 0.147 & 0.251 & $0.315^{* *}$ & $0.389 * *$ & 0.135 \\
\hline Mean pressure & 0.019 & 0.158 & $0.341 *$ & $0.254^{*}$ & $0.361 * *$ & 0.069 \\
\hline Ejection duration & 0.216 & 0.203 & $0.364 *$ & 0.193 & 0.140 & 0.090 \\
\hline SEVR & -0.191 & -0.208 & $-0.427 * *$ & -0.148 & -0.089 & 0.119 \\
\hline SP & 0.002 & 0.202 & $0.352 *$ & 0.178 & $0.308 * *$ & -0.013 \\
\hline DP & 0.023 & 0.154 & 0.234 & $0.320 * *$ & $0.378 * *$ & 0.144 \\
\hline HR & $0.291 *$ & 0.206 & $0.432 * *$ & 0.156 & 0.081 & 0.114 \\
\hline
\end{tabular}

**Significant at $P<0.01,{ }^{*}$ Significant at $P<0.05$. SP: Systolic pressure, DP: Diastolic pressure, SEVR: Subendocardial viability ratio, Aug. P: Augmentation pressure, AIx: Augmentation index, BMI: Body mass index, HR: Heart rate, PP: Pulse pressure

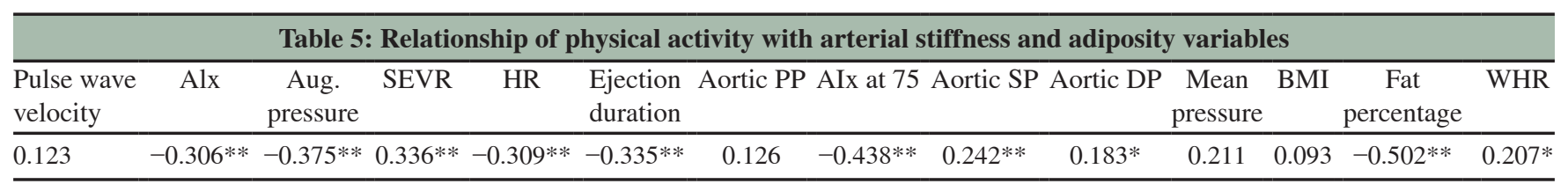

Correlation coefficients **Significant at $P<0.01$, $*$ Significant at $P<0.05$. SEVR: Subendocardial viability ratio, Aug. P: Augmentation pressure, Aug. index: AIx, BMI: Body mass index, WHR: Waist-hip-ratio, SP: Systolic pressure, DP: Diastolic pressure, HR: Heart rate, PP: Pulse pressure

number of significant correlations within the range of $0.3-0.5$. It is recognized that the contribution to the total variance is low (9-25\%), still leaving a large unaccounted variance. The following discussion recognizes this limitation.

The results show a strong relationship between adiposity derived from skinfold thickness and arterial stiffness derived from a less invasive carotid-radial pulse wave analysis. These results are similar to previous studies, which used similar and alternative methods. de Jongh et al. ${ }^{[12]}$ studied the relationship between visceral adiposity using magnetic resonance imaging, skinfold thickness and postocclusive skin capillary recruitment using a vascular microscope. They found that vascular recruitment was inversely related to inflammation score, visceral adiposity, and truncal/ extremities skinfold thickness. Whincup et al. ${ }^{[4]}$ studied the relationship between adiposity and arterial distensibility in adolescents. They measured the arterial distensibility using ultrasound and body fat using skinfold thickness, similar to the current study. They found a significant relationship between them in both sexes. There was a lower arterial distensibility in females in their study. Similarly, the females in the current study had higher arterial stiffness that includes ejection duration, PP, and AIx. In agreement with these results, Yasmin and Brown ${ }^{[13]}$ also found higher AIx in females using a similar radial pulse wave analysis.
These findings clearly show a need to have separate reference values for males and female. Yasmin and Brown ${ }^{[13]}$ also found a similar negative correlation between AIx and height. It confirms that there could be an earlier reflection of pulse waves in shorter people, which results in a lower AIx. It is also important to note that females also had a higher fat percentage as estimated by the measurement of the individual skinfold thickness of the biceps, triceps, and thigh. The current study showed significant relationships between obesity (BMI and WHR) and arterial stiffness similar to the study by Whincup et al. ${ }^{[4]}$ However, the relationships were more statistically significant in a number of variables in females [Table 4]. This may be due to the higher number of female participants. Nevertheless, the females had lower BMI compared with males, yet their fat percentage was significantly higher. Several studies have found that Asians have higher fat percentage and, in general, females have higher fat percentage compared with their BMI. ${ }^{[14,15]}$ It was suggested that it might be due to the difference in body type such as trunk/leg length in different ethnics and lifestyle factors. ${ }^{[14-17]}$ Thus, in the current study, the higher fat percentage may be the reason for the significant correlations found between more arterial stiffness variables and fat percentage in females. These findings suggest that fat percentage measured by skinfold thickness has more clinical importance than simple BMI measurements. 
Relationship between adiposity, insulin resistance/ hyperinsulinemia, and arterial stiffness

A possible mechanism for the positive relationship between adiposity and arterial stiffness is the increase in insulin resistance due to adiposity. ${ }^{[18,19]}$ Banerji et al. ${ }^{[20]}$ found a strong correlation between insulin resistance and total body fat as well as regional and subcutaneous fat in Asian Indians. They state that visceral fat increases with total body fat and this results in increased insulin resistance. Urakawa et al. ${ }^{[21]}$ observed a direct correlation between adiposity and oxidative stress. They state that adiposity increases the release of reactive oxygen species from leukocytes and thus increases the oxidative stress and leads to an increase in insulin resistance. Insulin resistance resulting in hyperinsulinemia leads to many of the following physiological reactions: (1) Sodium retention due to increased sodium absorption in the renal circulation $\operatorname{and}^{[2,23]}(2)$ increased body fat and its associations with over activity of autonomic nervous system especially sympathetic system at rest. ${ }^{[24,25]}$ Hyperinsulinemia is the main mechanism that triggers sympathetic activity. ${ }^{[26]}$ This results in an increase in resting heart rate and blood pressure. ${ }^{[27]}$ The positive relationship between heart rate, systolic blood pressure, and fat percentage in the current results [Table 4] confirms these findings. (3) Hyperinsulinemia increases the mitogenic activities that lead to vascular smooth muscle proliferation, increased collagen synthesis in the vascular wall and vascular hypertrophy. ${ }^{[28-30]}$ In addition, adiponectin, a protein derived from adipocytes, acts as a modulator for vascular smooth muscle proliferation. ${ }^{[31]}$ An increase in other inflammatory adipocytokines such as tumor necrosis factor- $\alpha$, interlekin-6, leptin, plasminogen activator inhibitor-1, angiotensinogen, resistin, and C-reactive protein (CRP) also have negative impacts on vascular structure. ${ }^{[32]}$ All these mechanisms ultimately affect the endothelium-dependent vasodilatation and increase vascular stiffness. ${ }^{[29,33]}$

Leptin was not measured in this study. Leptin is a protein, which regulates adiposity and increases in concentration when body fat percentage increases. ${ }^{[34]}$ Leptin is also found to be an important factor that increases sympathetic activity. ${ }^{[35]}$ Singhal et al. ${ }^{[36]}$ studied the relationship between leptin, body fat mass, and arterial distensibility. They found the arterial distensibility had a negative relationship with leptin concentration in blood and body fat mass derived from skinfold thickness. This negative relationship was irrespective of other inflammatory markers such as CRP, insulin, and lipids.

PWV had significant positive relationship with body adiposity variables in many previous studies. Sutton-Tyrrell et $a l^{[37]}$ found a strong relationship between visceral adiposity measured by computed tomography and PWV measure using Doppler flow signals on 2488 older adults with a mean age of 74 years. However, they found a weak correlation between PWV and the subcutaneous fat $(P=0.026)$. Wildman et al. ${ }^{[38]}$ also found a strong positive relationship between Doppler measures carotid-femoral PWV and BMI. Previous studies on Indian obese children ${ }^{[39]}$ and diabetic adults ${ }^{[40]}$ also found strong relationship between PWV and body fat. However, the current study results did not show any significant relationship of PWV with any adiposity variables. Carotid-radial PWV may therefore not be an early indicator of arterial stiffness in young Indian adults. This needs to be studied more to be confirmed.

\section{Physical activity}

The negative correlations between physical activity and fat percentage have been demonstrated in previous studies. Sakuragi et al. ${ }^{[5]}$ found a negative relationship between cardiac fitness and arterial stiffness (using carotid-femoral pulse wave analysis) as well as adiposity. However, there was no correlation between physical activity and BMI in the current study. Controversially, there was positive correlation between physical activity and WHR. This may be due to the differences in the other lifestyle factors among the participants. Thus, skinfold thickness may be a more valid method to measure body fat. However, it is also important to consider the factors other than physical activity that influence obesity such as ethnicity, parental obesity, dietary pattern, and sedentary behaviors such as watching television. $^{[41-43]}$

To the best of our knowledge, this is the first study in India to establish the relationship between adiposity and noninvasive brachial-radial arterial stiffness. The agreement between the current findings and previous studies confirms that the noninvasive arterial stiffness could be a marker for cardiovascular risks in young adults. The increase in the prevalence of obesity is seen in all the age groups and continuously developing globally. The current findings could be helpful for future studies and for developing diagnostic and preventive measures for cardiovascular risk at younger age groups.

\section{Limitations}

A larger number of participants could improve the significance of the results. It was not possible to control the dietary pattern and physical activities in the participants, and there was a wide range of these values. Measurement of blood lipids and inflammatory biomarkers such as leptin and CRP would have improved the strength this study. It was not possible in this study due to limited availability of funds.

\section{CONCLUSIONS}

Arterial stiffness measured by carotid-radial pulse wave analysis is strongly related to adiposity measured from 
skinfold thickness in young South Asian females. There are gender differences in arterial stiffness variables derived from pulse wave analysis. More controlled studies are necessary to improve the quality of the results using this less intrusive technique, the carotid-radial pulse wave analysis.

\section{Financial support and sponsorship}

Nil.

\section{Conflicts of interest}

There are no conflicts of interest.

\section{REFERENCES}

1. Mathers CD, Loncar D. Projections of global mortality and burden of disease from 2002 to 2030. PLoS Med 2006;3:e442.

2. Kelly T, Yang W, Chen CS, Reynolds K, He J. Global burden of obesity in 2005 and projections to 2030. Int J Obes (Lond) 2008;32:1431-7.

3. Chhatwal J, Verma M, Riar SK. Obesity among pre-adolescent and adolescents of a developing country (India). Asia Pac J Clin Nutr 2004:13:231-5

4. Whincup PH, Gilg JA, Donald AE, Katterhorn M, Oliver C, Cook DG, et al. Arterial distensibility in adolescents: The influence of adiposity, the metabolic syndrome, and classic risk factors. Circulation 2005;112:1789-97.

5. Sakuragi S, Abhayaratna K, Gravenmaker KJ, O'Reilly C, Srikusalanukul W, Budge MM, et al. Influence of adiposity and physical activity on arterial stiffness in healthy children: The lifestyle of our kids study. Hypertension 2009;53:611-6.

6. Acree LS, Montgomery PS, Gardner AW. The influence of obesity on arterial compliance in adult men and women. Vasc Med 2007;12:183-8.

7. Ferreira I, Twisk JW, van Mechelen W, Kemper HC, Seidell JC, Stehouwer CD. Current and adolescent body fatness and fat distribution: Relationships with carotid intima-media thickness and large artery stiffness at the age of 36 years. J Hypertens 2004;22:145-55.

8. Kemper HC, Post GB, Twisk JW, van Mechelen W. Lifestyle and obesity in adolescence and young adulthood: Results from the Amsterdam Growth And Health Longitudinal Study (AGAHLS). Int J Obes Relat Metab Disord 1999;23 Suppl 3:S34-40.

9. Juonala M, Järvisalo MJ, Mäki-Torkko N, Kähönen M, Viikari JS, Raitakari OT. Risk factors identified in childhood and decreased carotid artery elasticity in adulthood: The Cardiovascular Risk in Young Finns Study. Circulation 2005;112:1486-93.

10. Zebekakis PE, Nawrot T, Thijs L, Balkestein EJ, van der Heijden-Spek J, Van Bortel LM, et al. Obesity is associated with increased arterial stiffness from adolescence until old age. J Hypertens 2005;23:1839-46.

11. Durnin JV, Womersley J. Body fat assessed from total body density and its estimation from skinfold thickness: Measurements on 481 men and women aged from 16 to 72 years. Br J Nutr 1974;32:77-97.

12. de Jongh RT, Ijzerman RG, Serné EH, Voordouw JJ, Yudkin JS, de Waal HA, et al. Visceral and truncal subcutaneous adipose tissue are associated with impaired capillary recruitment in healthy individuals. J Clin Endocrinol Metab 2006;91:5100-6.

13. Yasmin, Brown MJ. Similarities and differences between augmentation index and pulse wave velocity in the assessment of arterial stiffness. QJM 1999;92:595-600.

14. Deurenberg-Yap M, Schmidt G, van Staveren WA, Deurenberg P. The paradox of low body mass index and high body fat percentage among
Chinese, Malays and Indians in Singapore. Int J Obes Relat Metab Disord 2000;24:1011-7.

15. Wang J, Thornton JC, Russell M, Burastero S, Heymsfield S, Pierson RN Jr. Asians have lower body mass index (BMI) but higher percent body fat than do whites: Comparisons of anthropometric measurements. Am J Clin Nutr 1994;60:23-8.

16. Novotny R, Daida YG, Grove JS, Le Marchand L, Vijayadeva V. Asian adolescents have a higher trunk: Peripheral fat ratio than Whites. J Nutr 2006;136:642-7.

17. Dudeja V, Misra A, Pandey RM, Devina G, Kumar G, Vikram NK. BMI does not accurately predict overweight in Asian Indians in northern India. Br J Nutr 2001;86:105-12.

18. Ross R, Aru J, Freeman J, Hudson R, Janssen I. Abdominal adiposity and insulin resistance in obese men. Am J Physiol Endocrinol Metab 2002;282:E657-63.

19. Garg A. Regional adiposity and insulin resistance. J Clin Endocrinol Metab 2004;89:4206-10.

20. Banerji MA, Faridi N, Atluri R, Chaiken RL, Lebovitz HE. Body composition, visceral fat, leptin, and insulin resistance in Asian Indian men. J Clin Endocrinol Metab 1999;84:137-44.

21. Urakawa H, Katsuki A, Sumida Y, Gabazza EC, Murashima S, Morioka $\mathrm{K}$, et al. Oxidative stress is associated with adiposity and insulin resistance in men. J Clin Endocrinol Metab 2003;88:4673-6.

22. ter Maaten JC, Bakker SJ, Serné EH, ter Wee PM, Donker AJ, Gans RO. Insulin's acute effects on glomerular filtration rate correlate with insulin sensitivity whereas insulin's acute effects on proximal tubular sodium reabsorption correlation with salt sensitivity in normal subjects. Nephrol Dial Transplant 1999;14:2357-63.

23. DeFronzo RA, Goldberg M, Agus ZS. The effects of glucose and insulin on renal electrolyte transport. J Clin Invest 1976;58:83-90.

24. Chen GY, Hsiao TJ, Lo HM, Kuo CD. Abdominal obesity is associated with autonomic nervous derangement in healthy Asian obese subjects. Clin Nutr 2008;27:212-7.

25. Scherrer U, Randin D, Tappy L, Vollenweider P, Jéquier E, Nicod P. Body fat and sympathetic nerve activity in healthy subjects. Circulation 1994;89:2634-40.

26. Vollenweider P, Tappy L, Randin D, Schneiter P, Jéquier E, Nicod P, et al. Differential effects of hyperinsulinemia and carbohydrate metabolism on sympathetic nerve activity and muscle blood flow in humans. J Clin Invest 1993;92:147-54.

27. Baba $R$, Koketsu $M$, Nagashima $M$, Inasaka $H$, Yoshinaga $M$, Yokota M. Adolescent obesity adversely affects blood pressure and resting heart rate. Circ J 2007;71:722-6.

28. Draznin B. Mechanism of the mitogenic influence of hyperinsulinemia. Diabetol Metab Syndr 2011;3:10.

29. DeFronzo RA, Ferrannini E. Insulin resistance. A multifaceted syndrome responsible for NIDDM, obesity, hypertension, dyslipidemia, and atherosclerotic cardiovascular disease. Diabetes Care 1991;14:173-94.

30. Zimlichman R, Zeidel L, Gefel D, Barg J, Shahar C, Nakash Y, et al. Insulin induces medial hypertrophy of myocardial arterioles in rats. Am J Hypertens 1995;8:915-20.

31. Arita Y, Kihara S, Ouchi N, Maeda K, Kuriyama H, Okamoto Y, et al. Adipocyte-derived plasma protein adiponectin acts as a platelet-derived growth factor-BB-binding protein and regulates growth factor-induced common postreceptor signal in vascular smooth muscle cell. Circulation 2002;105:2893-8.

32. Lau DC, Dhillon B, Yan H, Szmitko PE, Verma S. Adipokines: Molecular links between obesity and atheroslcerosis. Am J Physiol Heart Circ Physiol 2005;288:H2031-41.

33. Kotchen TA. Insulin resistance and hypertension. In: Schrier RW, editor. Atlas of Diseases of the Kidney. Vol. 3. USA: Blackwell Science; 1999.

34. Considine RV, Sinha MK, Heiman ML, Kriauciunas A, Stephens TW, Nyce MR, et al. Serum immunoreactive-leptin concentrations in normal-weight and obese humans. N Engl J Med 1996;334:292-5. 


\section{Radhakrishnan J, et al.: Body adiposity and arterial stiffness}

35. Haynes WG, Sivitz WI, Morgan DA, Walsh SA, Mark AL. Sympathetic and cardiorenal actions of leptin. Hypertension 1997;30 (3 Pt 2):619-23.

36. Singhal A, Farooqi IS, Cole TJ, O'Rahilly S, Fewtrell M, Kattenhorn M, et al. Influence of leptin on arterial distensibility: A novel link between obesity and cardiovascular disease? Circulation 2002;106:1919-24.

37. Sutton-Tyrrell K, Newman A, Simonsick EM, Havlik R, Pahor M, Lakatta E, et al. Aortic stiffness is associated with visceral adiposity in older adults enrolled in the study of health, aging, and body composition. Hypertension 2001;38:429-33.

38. Wildman RP, Mackey RH, Bostom A, Thompson T, Sutton-Tyrrell K. Measures of obesity are associated with vascular stiffness in young and older adults. Hypertension 2003;42:468-73.

39. Pandit DS, Khadilkar AV, Chiplonkar SA, Khadilkar VV, Kinare AS. Arterial stiffness in obese children: Role of adiposity and physical activity. Indian J Endocrinol Metab 2014;18:70-6.

40. Anoop S, Misra A, Bhardwaj S, Gulati S. High body fat and low muscle mass are associated with increased arterial stiffness in Asian Indians in North India. J Diabetes Complications 2015;29:38-43.

41. Salmon J, Bauman A, Crawford D, Timperio A, Owen N. The association between television viewing and overweight among Australian adults participating in varying levels of leisure-time physical activity. Int J Obes Relat Metab Disord 2000;24:600-6.

42. Maffeis C, Talamini G, Tatò L. Influence of diet, physical activity and parents' obesity on children's adiposity: A four-year longitudinal study. Int J Obes Relat Metab Disord 1998;22:758-64.

43. Gordon-Larsen P, Adair LS, Popkin BM. Ethnic differences in physical activity and inactivity patterns and overweight status. Obes Res 2002;10:141-9.

Address correspondence to:

Dr. Jeyasundar Radhakrishnan,

Department of Medicine, University of Alberta, 2-132 Li Ka Shing Centre, Edmonton, AB T6G 2E1, Canada. E-mail:jeyasundar@gmail.com 